\title{
Use of Growth Hormone in the IVF Treatment of Women With Poor Ovarian Reserve
}

\author{
Roger J. Hart ${ }^{1,2 *}$ \\ ${ }^{1}$ Division of Obstetrics and Gynaecology, University of Western Australia, Perth, WA, Australia, ${ }^{2}$ Fertility Specialists of \\ Western Australia, Bethesda Hospital, Claremont, WA, Australia
}

OPEN ACCESS

Edited by:

Tom Kelsey,

University of St. Andrews,

United Kingdom

Reviewed by:

Kannamannadiar Jayaprakasan,

University of Nottingham,

United Kingdom

Rong Yuan,

Southern Illinois University

Carbondale, United States

*Correspondence:

Roger J. Hart

roger.hart@uwa.edu.au

Specialty section:

This article was submitted to Endocrinology of Aging,

a section of the journal

Frontiers in Endocrinology

Received: 16 April 2019

Accepted: 09 July 2019

Published: 24 July 2019

Citation:

Hart RJ (2019) Use of Growth

Hormone in the IVF Treatment of Women With Poor Ovarian Reserve.

Front. Endocrinol. 10:500.

doi: 10.3389/fendo.2019.00500
Growth hormone $(\mathrm{GH})$ has been used as an adjunct in the field of female infertility treatment for more than 25 years, although, apart from treating women with $\mathrm{GH}$ deficiency its role has not yet been clarified. Contributing to this lack of clarity is that several underpowered studies have been performed on women undergoing IVF treatment, with a previous "poor response" to ovarian stimulation, which have suggested a favorable outcome. Meta-analysis of randomized controlled trials has demonstrated a benefit for the use of the adjunct growth hormone, in comparison to placebo; with reductions in the duration of ovarian stimulation required prior to oocyte retrieval, with a greater number of oocytes collected, and improvements in many of the early clinical parameters with the use of $\mathrm{GH}$. However, no benefit of an increased chance of a live birth with the use of growth hormone for the "poor responding" patient has been determined. Consequently the role of $\mathrm{GH}$ to treat a woman with a poor response to ovarian stimulation cannot be supported on the basis of the available evidence. However, the place for $\mathrm{GH}$ in the treatment of women undergoing IVF may yet still be determined, as it is also used, without firm evidence of benefit; for women with poor embryonic development, poor endometrial development and for women who do not conceive despite multiple embryo transfers (recurrent implantation failure).

Keywords: growth hormone, IVF, ovarian reserve, poor responder, embryo quality

\section{INTRODUCTION}

Growth hormone $(\mathrm{GH})$ is a peptide hormone secreted from the pituitary gland in response to growth hormone releasing hormone, and its secretion is inhibited by growth hormone inhibiting hormone (somatostatin) released form the hypothalamus into the hypophyseal portal system surrounding the pituitary gland. GH is released from the somatotroph cells of the anterior pituitary, with a frequency and amplitude that changes during the day. Its peak secretion occurs after sleep commences, and is age and sex dependent, with maximal secretion occurring around puberty, and its pulsatile release is further modulated by sleep patterns, diet, exercise and stress. As GH is not fat soluble; it exerts its effects via secondary messengers. The main end-point of GH activity is the liver, where GH leads to the synthesis of insulin- like growth factor 1 (IGF-1), which is consequently the major method of action of GH.

In the ovary IGF-1 receptors are present within oocytes, granulosa, and theca cells (1). With respect to the involvement of GH in ovarian function, Zhou et al. (2) demonstrated that IGF-1 acts via its receptor (IGF-1R) in the granulosa cells of the ovarian follicles to stimulate AKT 
and gene expression by follicular stimulating hormone (FSH). IGF-1 facilitates, or potentiates, the action of FSH in folliculogenesis, and assists with granulosa cell differentiation, with the largest follicles containing the highest concentrations of IGF-1 (2). Studies using murine models suggest IGF-1 is integral to follicular recruitment (3), assists in acquisition of FSH receptors and oocyte maturation (4), and the inhibition of follicular apoptosis $(5,6)$. Studies performed on human granulosa cells demonstrate that $\mathrm{GH}$ co-treatment induces the receptor density of key regulators of folliculogenesis, when compared to the granulosa cells of non-GH-treated patients of the same age and ovarian reserve (7). These key regulators consist of the receptors for: $\mathrm{GH}, \mathrm{FSH}$, luteinising hormone, and the receptor of an important regulator of oocyte development; bone-morphogenic protein $1 \mathrm{~B}$.

Evidence derived from human clinical observational data provides a rationale for the use $\mathrm{GH}$ in in-vitro fertilization (IVF) treatment. As the follicular fluid IGF-1 concentrations of women, at oocyte retrieval, are proportional to the number of developing follicles, and are inversely related to the ovarian stimulation required, both in amount and duration (8). Furthermore, follicular fluid concentrations of $\mathrm{GH}$ have been correlated with the chance of a clinical pregnancy (9), and the follicular concentration of $\mathrm{GH}$ has been reported to be greatest in the follicle that leads to successful oocyte fertilization, embryo development and implantation (10).

As $\mathrm{GH}$ was believed to be integral to folliculogenesis, it has been used as an adjunct in ovulation induction, and IVF, for over 25 years (11). It is an essential requirement in the treatment of infertility for women with GH deficiency, as many such women will have a disorder of ovulation $(12,13)$. Indeed, in line with the study by Zhou et al. (2), Homburg et al. (14) performed a randomized controlled trial of women undergoing ovulation induction, which demonstrated that the requirement for gonadotrophins was reduced for women who were coadministered GH during ovarian stimulation.

As described, GH has been used for many years in the treatment of female infertility to assist with ovulation induction (14), however, it is the use of GH as an adjunct in IVF treatment where most debate has occurred (15). GH has been employed for all women embarking on IVF treatment $(16,17)$, for women with polycystic ovary syndrome $(18,19)$, for women responding sub-optimally to ovarian stimulation in an IVF cycle (20), for "older" women (7), and for women with perceived poor oocyte or embryo quality (21). Although, interestingly it is perhaps not as a therapy to improve ovarian response, or oocyte quality, where any benefit of GH may lie, as a recent Chinese study suggests it may offer a favorable benefit for women undergoing IVF treatment who have a thin endometrium resistant to any therapy (22).

Although lacking FDA approval for its use in an IVF cycle, other than in the setting of GH deficiency, GH is most commonly used as an adjunct to ovarian stimulation for women who had a poor response to ovarian stimulation in a preceding IVF cycle. Despite the 25 years of use of GH to assist in the treatment of female infertility, its role in IVF treatment is still debated today (15). This is in part due to the problems inherent with the reporting of underpowered studies of patients with a poor prognosis for pregnancy. The reason these women, with a poor prognosis for pregnancy, have a low chance of conceiving is that they may well have already undergone several unsuccessful IVF treatment cycles, and are perceived to have either a poor response to stimulation, or suffer with poor oocyte quality. Furthermore, difficulty arises in determining whether $\mathrm{GH}$ has a role in the treatment of female infertility as; the drug is expensive, it is unclear what is the appropriate dose to use, when the GH treatment should be commenced, or even in which sub-group of patients it should be used (15). However, the focus of this review is the use of GH for women with a poor ovarian reserve. Poor ovarian reserve is now generally classified by using a standardized definition, the Bologna criteria is the definition most widely embraced (23); requiring two of the following features:

(i) advanced maternal age ( $\geq 40$ years) or other risk factors for poor ovarian response

(ii) a previous poor ovarian response ( $\leq 3$ oocytes with a conventional stimulation protocol)

(iii) an abnormal ovarian response test (antral follicle count $<5-7$ or anti-Müllerian hormone $<0.5-1.1 \mathrm{ng} / \mathrm{ml}[<3.6-$ $7.9 \mathrm{nmol} / \mathrm{l}])$.

Although this definition has its detractors (24), it is useful to employ standard definitions when studying populations, as this enables comparisons with other studies performed in similar sub-sets of women undergoing fertility treatment, although there may be other subtle differences that may arise related to other differences, such as ethnicity. However, despite the introduction of this standardized definition, the majority of the studies of the use of $\mathrm{GH}$ were performed prior to the introduction of this definition. Consequently, each study has differing inclusion criteria for the subjects studied.

\section{THE USE OF GROWTH HORMONE FOR POOR RESPONDERS UNDERGOING IVF TREATMENT}

The first randomized controlled trials of the use of $\mathrm{GH}$ as an adjunct for all women undergoing IVF treatment, were performed two decades ago by Tapanainen (16) and Younis (17). These studies did not detect any differences in any clinical parameter studied with the addition of $\mathrm{GH}(16,17)$. Subsequently the majority of the studies of the use of GH in IVF treatment have been restricted to women who respond poorly to ovarian stimulation (15, 20, 25-28). Despite an apparent benefit noted when using $\mathrm{GH}$, for some of the clinical parameters studied, the studies have been characterized by substantial differences in the inclusion criteria, and differences in the dose and timing of the GH administration, leading to a lack of clarity around any potential benefit.

The largest randomized study performed to date was an open label study performed by Dakhly et al. (28). This study included 240 women who met the Bologna criteria for poor ovarian response, who undertook an IVF cycle using a "longdown regulation" protocol. This approach initiates pituitary 
desensitization with the use of a gonadotrophin releasing hormone analog commenced prior to ovarian stimulation. The patients in the active arm commenced $7.5 \mathrm{IU}$ GH at the start of pituitary down-regulation, which due to the purported method action of $\mathrm{GH}$ has a sound rationale (29). The primary outcome was the live birth rate, using all available fresh and frozen embryos generated. Consistent with previous studies, this group demonstrated a benefit with the use of $\mathrm{GH}$, with respect to; a shorter duration of stimulation, less FSH requirement, a higher serum oestradiol concentration at oocyte retrieval, more oocytes collected, the development of more fertilized oocytes and more embryos generated. However, ultimately there was no difference in the cumulative live birth between the two groups 18.3 vs. $14.7 \%$, for use of $\mathrm{GH}$ vs. control respectively (28).

The most recent published randomized trial performed to date is the Australian multi-center "LIGHT" study (30). Nonobese women of 40 years of age, or younger, were eligible for inclusion if they had responded poorly in at least one previous IVF cycle ( $\leq 5$ oocytes collected), on a high dose of ovarian stimulation. They were excluded if they had a recorded serum FSH concentration $>15 \mathrm{IU} / \mathrm{l}$. They were randomized to receive either; 12iu $\mathrm{GH}$ from the day of ovarian stimulation, or placebo, which was administered daily in a double-blind protocol (30). The majority of embryo transfers were of a single blastocyst, and the data was analyzed by intention to treat analysis. Of those women that achieved an oocyte retrieval, there was no difference in the chance of a live birth between those women that were administered $\mathrm{GH}$, and those that received the placebo (14.5 vs. $13.7 \%)$. However, more women achieved an oocyte retrieval in the GH group, $95.4 \%$, in comparison to $78.5 \%$ of women in the placebo group, and they had, on average, one more oocyte collected (5 vs. 4 oocytes). Although, there were no differences in the chances of the women in the $\mathrm{GH}$ group reaching an embryo transfer, and there were no differences detected in embryonic development between the two groups (30).

Using data from the LIGHT study, but without the inclusion of the Dakhly study, the most up to data meta-analysis was published in 2017 (15) (Figures 1A-H). The data within the meta-analysis was derived from studies that used heterogeneous definitions of a "poor responder," and the doses, timing, and duration of administration of GH varied substantially (31-41). Furthermore, some studies did not report their data per cycle started, as many patients will not have achieved an oocyte retrieval or an embryo transfer, leading to a potential bias in the results (15). This meta-analysis did not demonstrate a benefit of the chance of proceeding to an oocyte retrieval, however there was a benefit of the use of $\mathrm{GH}$ with respect to a shorter time taken to oocyte retrieval and an increased number of oocytes were collected. More oocytes achieved fertilization with the use of $\mathrm{GH}$, but there was no increase in the chance in having an embryo to available to transfer. More patients had a positive pregnancy test after GH administration, and achieved a clinical pregnancy, but there was no overall improvement in the live birth rate reported in this metaanalysis (15).

\section{DISCUSSION}

For women who respond poorly to ovarian stimulation in an IVF cycle, it appears that there is no overall benefit of the use of $\mathrm{GH}$, as $\mathrm{GH}$ does not lead to an improvement in the chance of a live birth. Live birth is the ultimate end-point of relevance, and should be considered the primary outcome of all infertility interventions. Certainly it would appear from the evidence cited, that the use of $\mathrm{GH}$ leads to a reduced time to oocyte retrieval and more oocytes collected, although ultimately no increase in the chance of a live birth. Understandably, in clinical practice, clinicians and patients alike, are encouraged by the opportunity to have more oocytes collected with the use of GH, as they may perceive this as giving them the potential of a more successful outcome. This leads to the inherent uncertainty of the role of GH in IVF treatment, as patients are often in a vulnerable position being desperate to conceive, and the opportunity of having more oocytes collected to them is viewed positively, and consequently they may apply pressure on their IVF doctor to prescribe GH. Although the use of $\mathrm{GH}$ has a good safety profile, it is very expensive. Hence, the treatment is for many cost prohibitive and many patients will not be able to afford the treatment. For patients willing to pay for the intervention, doctors should use $\mathrm{GH}$ under caution, as IVF is not a defined indication for its use, and the evidence cited does not support it use for women with a poor response to ovarian stimulation. It is important to state that as GH use is "off-label" couples are warned of potential unknown consequences for the offspring. Indeed the authors of the LIGHT study stated "While congenital abnormalities were not different between groups, the number in the growth hormone treatment group warrants ongoing surveillance of treatment with this hormone."

A concern that is as yet unanswered, is the discrepancy between the favorable influences on pregnancy rates that is not reflected in live birth rates. It is unclear as to whether the studies performed are underpowered for live birth outcome data, or whether it is that GH may just recruit an oocyte that is poor in quality and subsequently results in an early pregnancy loss. Only further studies will help to clarify this apparent dichotomy.

However, GH may not have found its appropriate indication, as it may be that $\mathrm{GH}$ assists a sub-group of poor responder patients; women with poor oocyte and/or poor embryonic development (21). However, no randomized studies have been performed on these sub-groups of patients, perhaps due to the difficulties in defining a "poor oocyte" or "poor embryonic development." Furthermore, many women will meet the criteria of a "poor responder," but the populations of women within this criteria can be disparate, for instance, they may differ with respect to; the woman's age (a significant marker of oocyte quality), or they may differ with respect to the number of un-recruited follicles when stimulated. For example, a 40-year-old woman with no antral follicles on ultrasound examination is evidently a different clinical scenario to a woman of 30 years of age with a few un-recruited antral follicles visualized on ultrasound, however they both meet the criteria of a poor responder (23). This has led to clinicians further exploring the definition, and now describing a group of patients as the "sub-optimal responder" 


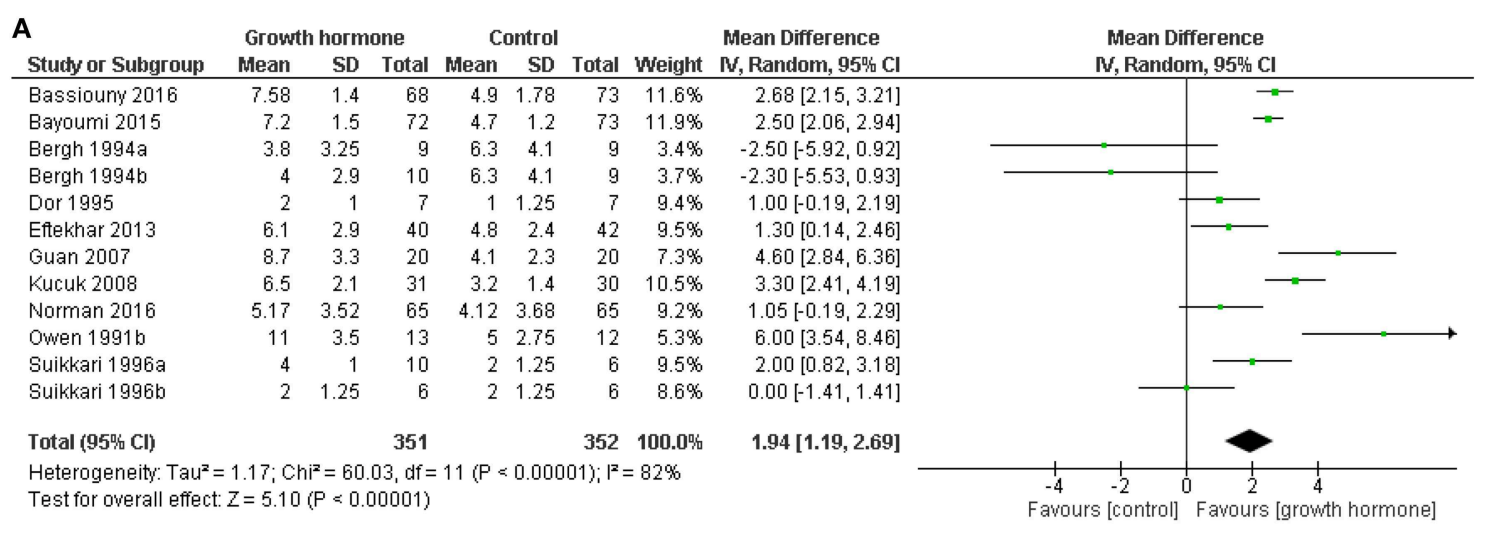

Mean Difference Mean Difference

$\mathrm{N}$, Random, 95\% $\mathrm{Cl}$ $\mathrm{N}$, Random, $95 \% \mathrm{Cl}$

B

Growth hormone Control Odds Ratio Study or Subgroup Events Total Events Total Weight $\mathrm{M}-\mathrm{H}$, Random, 95\% $\mathrm{Cl}$ $\begin{array}{lllllll}\text { Bassiouny 2016 } & 64 & 68 & 68 & 73 & 11.5 \% & 1.18[0.30,4.58]\end{array}$ Bayoumi 2015 Bergh 1994a Bergh 1994b Dor 1995 Eftekhar 2013

Howles 1999 Kucuk 2008 Norman 2016 Owen $1991 \mathrm{~b}$ Suikkari 1996a Suikkari 1996 b

Total (95\% Cl) $\begin{array}{lcc}\text { Total events } & 403 & 395 \\ \text { Heterogeneity: } \text { Tau }^{2}=0.00 ; \mathrm{Chi}^{2}=7.50, \mathrm{df}=8(\mathrm{P}=0.48) ; \mathrm{I}^{2}=0 \%\end{array}$

Test for overall effect: $Z=1.64(P=0.10)$

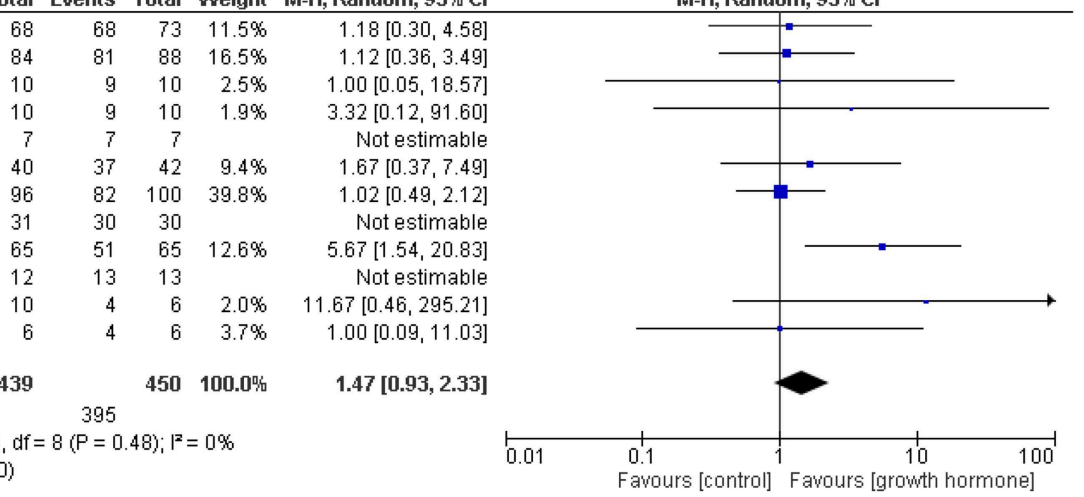

C Growth hormone Control Mean Difference Mean Difference Study or Subgroup Mean SD Total hean SD Total Weight N, Random, 95\% Cl \begin{tabular}{lllllllll}
\hline Bassiouny 2016 & 10.77 & 1.51 & 68 & 12.02 & 1.46 & 73 & $15.3 \%$ & $-1.25[-1.74,-0.76]$
\end{tabular} $\begin{array}{lllllllll}\text { Bayoumi 2015 } & 10.3 & 1.2 & 72 & 11.7 & 1.2 & 73 & 16.1 \% & -1.40[-1.79,-1.01]\end{array}$ $\begin{array}{lllllllll}\text { Bergh 1994a } & 10 & 1.75 & 10 & 10 & 2.75 & 9 & 4.3 \% & 0.00[-2.10,2.10]\end{array}$ $\begin{array}{lllllllll}\text { Bergh 1994b } & 10 & 1.75 & 10 & 10 & 2.75 & 9 & 4.3 \% & 0.00[-2.10,2.10]\end{array}$

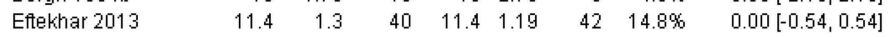
$\begin{array}{lllllllll}\text { Kucuk 2008 } & 10.5 & 1 & 31 & 12.5 & 1.4 & 30 & 14.1 \% & -2.00[-2.61,-1.39]\end{array}$ $\begin{array}{lllllllll}\text { Norman } 2016 & 9.26 & 2.06 & 65 & 9.91 & 3.14 & 65 & 11.2 \% & -0.65[-1.56,0.26]\end{array}$

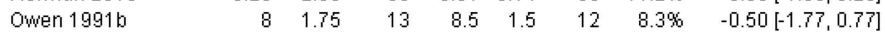
$\begin{array}{lllllllll}\text { Suikkari 1996a } & 14 & 1.5 & 10 & 15 & 1.75 & 6 & 5.9 \% & -1.00[-2.68,0.68]\end{array}$ Suikkari $1996 \mathrm{~b}$

Total (95\% Cl)

325

$325100.0^{\circ}$

Heterogeneity: $\mathrm{Tau}^{2}=0.36 ; \mathrm{Chi}^{2}=30.76, \mathrm{df}=9(\mathrm{P}=0.0003) ; \mathrm{I}^{2}=71 \%$

Test for overall effect: $Z=3.65(\mathrm{P}=0.0003)$



D

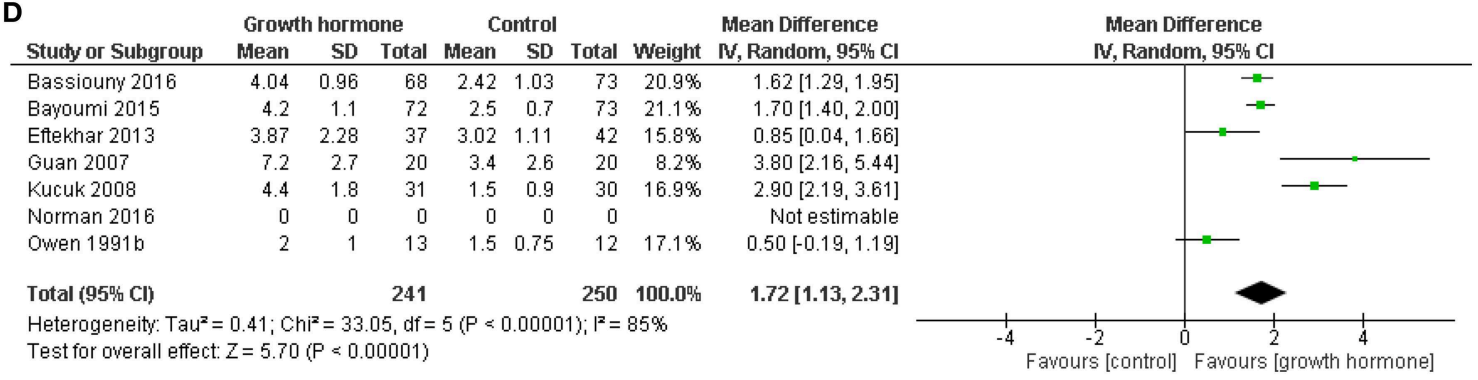




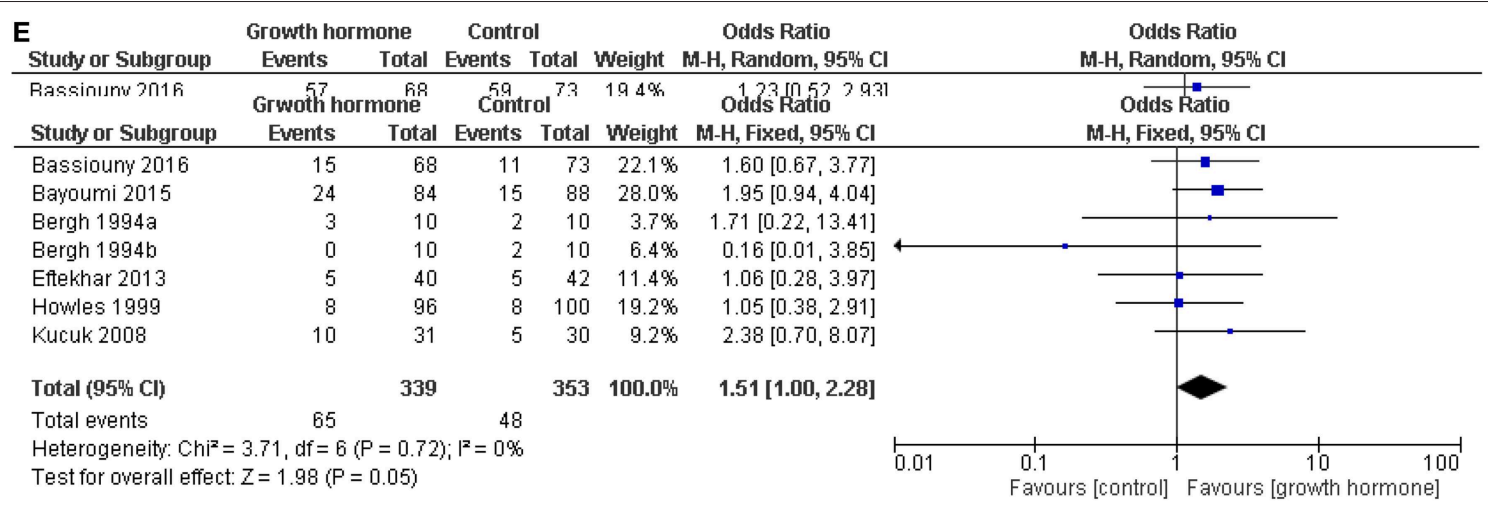

$\mathbf{F}$



G Stucty or Subgroup Events Total Events Total Weight M-H, Fixed, 95\% Cl

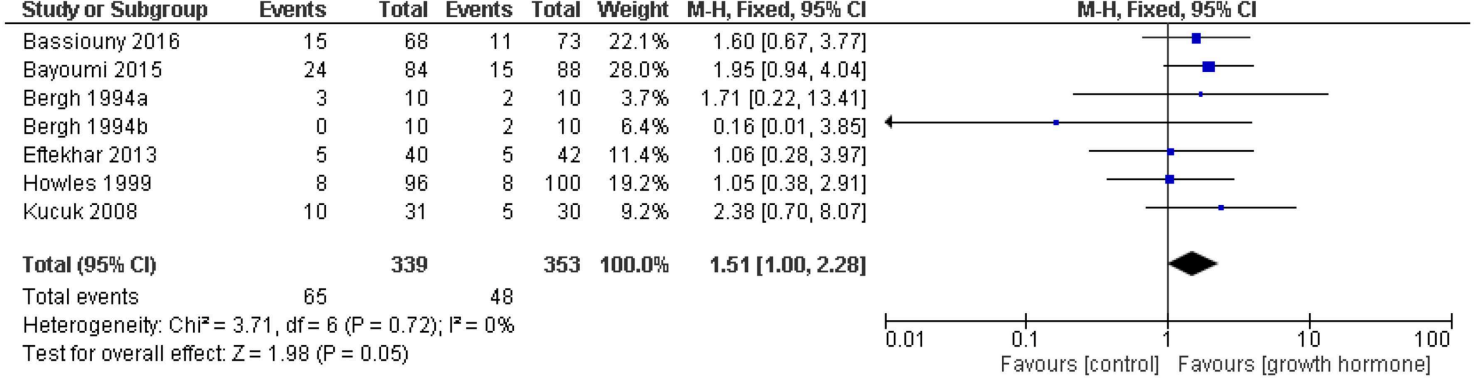

H

Growth hormone Control Odds Ratio

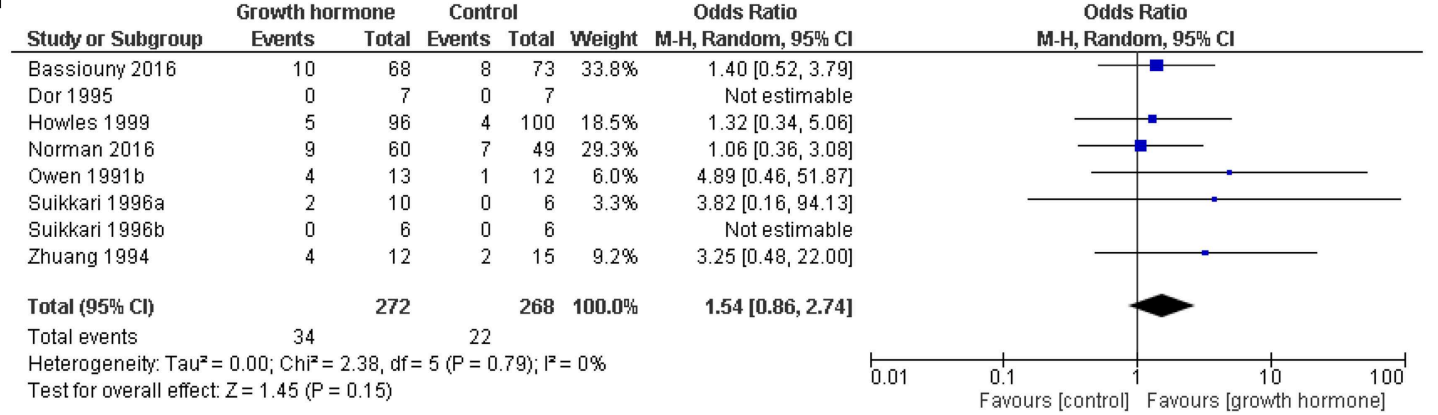

FIGURE 1 | Meta-analysis of the use of GH in poor responders. Forest plots of outcomes from the use of growth hormone in "poor responders" undergoing ovarian stimulation. Where possible data presented per cycle started (median and range converted to mean and std. dev.) Software RevMan Version 5.3. Copenhagen: The Nordic Cochrane Centre, The Cochrane Collaboration, 2014. Reproduced with permission from Hart et al. (15). (A) Forest plot of comparison: oocytes collected per cycle started. Not all patients reached oocyte retrieval. (B) Patients reached oocyte retrieval and had at least one oocyte retrieved. (C) The duration of stimulation. (D) Number of fertilized oocytes for women per cycle started (some data is presented by patients who had oocytes retrieved). (E) Patients with an embryo available for transfer per cycle started. (F) Positive pregnancy test per cycle started. (G) Clinical pregnancy per cycle started. (H) Live birth per cycle started (15, 31-41). 
(42). Furthermore, it is possible that the indication for GH may not reside with either the poor responding patient or the patient with poor embryonic development; as it may ultimately be used for patients with poor endometrial development, or even in patients with recurrent implantation failure (22, 43-45).

\section{CONCLUSION}

Growth hormone has been used as an adjunct in fertility treatment for over 25 years, although apart from the treatment of women with $\mathrm{GH}$ deficiency its role has still to be clarified. Many underpowered studies have been performed on women with a poor response to ovarian stimulation. While $\mathrm{GH}$ almost universally appears to reduce the duration of ovarian stimulation

\section{REFERENCES}

1. Buyalos RP. Insulin-like growth factors: clinical experience in ovarian function. Am J Med. (1995) 98:55S-66S. doi: 10.1016/S0002-9343(99)80060-6

2. Zhou P, Baumgarten SC, Wu Y, Bennett J, Winston N, Hirshfeld-Cytron J, et al. IGF-I signaling is essential for FSH stimulation of AKT and steroidogenic genes in granulosa cells. Mol Endocrinol. (2013) 27:51123. doi: 10.1210/me.2012-1307

3. Baker J, Hardy MP, Zhou J, Bondy C, Lupu F, Bellve AR, et al. Effects of an Igfl gene null mutation on mouse reproduction. Mol Endocrinol. (1996) 10:903-18. doi: 10.1210/mend.10.7.8813730

4. Zhou J, Kumar TR, Matzuk MM, Bondy C. Insulin-like growth factor I regulates gonadotropin responsiveness in the murine ovary. Mol Endocrinol. (1997) 11:1924-33. doi: 10.1210/mend.11.13.0032

5. Bachelot A, Monget P, Imbert-Bollore P, Coshigano K, Kopchick JJ, Kelly $\mathrm{PA}$, et al. Growth hormone is required for ovarian follicular growth. Endocrinology. (2002) 143:4104-12. doi: 10.1210/en.2002-220087

6. Chun SY, Billig H, Tilly JL, Furuta I, Tsafriri A, Hsueh AJ. Gonadotropin suppression of apoptosis in cultured preovulatory follicles: mediatory role of endogenous insulin-like growth factor I. Endocrinology. (1994) 135:184553. doi: 10.1210/endo.135.5.7525255

7. Regan SLP, Knight PG, Yovich JL, Arfuso F, Dharmarajan A. Growth hormone during in vitro fertilization in older women modulates the density of receptors in granulosa cells, with improved pregnancy outcomes. Fertil Steril. (2018) 110:1298-310. doi: 10.1016/j.fertnstert.2018.08.018

8. Oosterhuis GJ, Vermes I, Lambalk CB, Michgelsen HW, Schoemaker J. Insulin-like growth factor (IGF)-I and IGF binding protein-3 concentrations in fluid from human stimulated follicles. Hum Reprod. (1998) 13:2859. doi: 10.1093/humrep/13.2.285

9. Mendoza C, Ruiz-Requena E, Ortega E, Cremades N, Martinez F, Bernabeu R, et al. Follicular fluid markers of oocyte developmental potential. Hum Reprod. (2002) 17:1017-22. doi: 10.1093/humrep/17.4.1017

10. Mendoza C, Cremades N, Ruiz-Requena E, Martinez F, Ortega E, Bernabeu S, et al. Relationship between fertilization results after intracytoplasmic sperm injection, and intrafollicular steroid, pituitary hormone and cytokine concentrations. Hum Reprod. (1999) 14:628-35. doi: 10.1093/humrep/14.3.628

11. Homburg R, Eshel A, Abdalla HI, Jacobs HS. Growth hormone facilitates ovulation induction by gonadotrophins. Clin Endocrinol. (1988) 29:1137. doi: 10.1111/j.1365-2265.1988.tb00252.x

12. Spiliotis BE. Growth hormone insufficiency and its impact on ovarian function. Ann N Y Acad Sci. (2003) 997:77-84. doi: 10.1196/annals.1290.009

13. Park JK, Murphy AA, Bordeaux BL, Dominguez CE, Session DR. Ovulation induction in a poor responder with panhypopituitarism: a case report and review of the literature. Gynecol Endocrinol. (2007) 23:826. doi: 10.1080/09513590601137533

14. Homburg R, West C, Torresani T, Jacobs HS. Cotreatment with human growth hormone and gonadotropins for induction required for oocyte retrieval, and lead to the collection of a greater number of oocytes than women who received a placebo, and many of the early clinical parameters appear favorable; there is no evidence to demonstrate an increased chance of a live birth for a woman who receives $\mathrm{GH}$ for this indication. Whether the role of GH resides in the treatment of poor oocyte quality, or to treat the "sub-optimal" responder, or in the treatment of "the thin endometrium" or "recurrent implantation failure" awaits further investigation and clarification.

\section{AUTHOR CONTRIBUTIONS}

The author confirms being the sole contributor of this work and has approved it for publication. of ovulation: a controlled clinical trial. Fertil Steril. (1990) 53:254-60. doi: 10.1016/S0015-0282(16)53277-4

15. Hart RJ, Rombauts L, Norman RJ. Growth hormone in IVF cycles: any hope? Curr Opin Obstet Gynecol. (2017) 29:11925. doi: $10.1097 /$ GCO. 0000000000000360

16. Tapanainen J, Martikainen H, Voutilainen R, Orava M, Ruokonen A, Ronnberg L. Effect of growth hormone administration on human ovarian function and steroidogenic gene expression in granulosa-luteal cells. Fertil Steril. (1992) 58:726-32. doi: 10.1016/S0015-0282(16)55319-9

17. Younis JS, Simon A, Koren R, Dorembus D, Schenker JG, Laufer N. The effect of growth hormone supplementation on in vitro fertilization outcome: a prospective randomized placebo-controlled double-blind study. Fertil Steril. (1992) 58:575-80. doi: 10.1016/S0015-0282(16)55266-2

18. Huang ZH, Baxter RC, Hughes SM, Matson PL, Lieberman BA, Morris ID. Supplementary growth hormone treatment of women with poor ovarian response to exogenous gonadotrophins: changes in serum and follicular fluid insulin-like growth factor-1 (IGF-1) and IGF binding protein-3 (IGFBP-3). Hum Reprod. (1993) 8:850-7. doi: 10.1093/oxfordjournals.humrep.a138153

19. Homburg R, Levy T, Ben-Rafael Z. Adjuvant growth hormone for induction of ovulation with gonadotrophin-releasing hormone agonist and gonadotrophins in polycystic ovary syndrome: a randomized, double-blind, placebo controlled trial. Hum Reprod. (1995) 10:2550-3. doi: 10.1093/oxfordjournals.humrep.a135743

20. Duffy JM, Ahmad G, Mohiyiddeen L, Nardo LG, Watson A. Growth hormone for in vitro fertilization. Cochrane Database Syst Rev. (2010) 2010:CD000099. doi: 10.1002/14651858.CD000099.pub3

21. Hazout A, Junca A, Menezo Y, Demouzon J, Cohen-Bacrie P. Effect of growth hormone on oocyte competence in patients with multiple IVF failures. Reprod Biomed Online. (2009) 18:664-70. doi: 10.1016/S1472-6483(10)60011-9

22. Cui N, Li AM, Luo ZY, Zhao ZM, Xu YM, Zhang J, et al. Effects of growth hormone on pregnancy rates of patients with thin endometrium. J Endocrinol Invest. (2019) 42:27-35. doi: 10.1007/s40618-018-0877-1

23. Ferraretti AP, La Marca A, Fauser BC, Tarlatzis B, Nargund G, Gianaroli $\mathrm{L}$, et al. ESHRE consensus on the definition of 'poor response' to ovarian stimulation for in vitro fertilization: the Bologna criteria. Hum Reprod. (2011) 26:1616-24. doi: 10.1093/humrep/der092

24. Younis JS, Ben-Ami M, Ben-Shlomo I. The Bologna criteria for poor ovarian response: a contemporary critical appraisal. J Ovarian Res. (2015) 8:76. doi: 10.1186/s13048-015-0204-9

25. Kolibianakis EM, Venetis CA, Diedrich K, Tarlatzis BC, Griesinger G. Addition of growth hormone to gonadotrophins in ovarian stimulation of poor responders treated by in-vitro fertilization: a systematic review and meta-analysis. Hum Reprod Update. (2009) 15:613-22. doi: 10.1093/humupd/dmp026

26. Kyrou D, Kolibianakis EM, Venetis CA, Papanikolaou EG, Bontis J, Tarlatzis BC. How to improve the probability of pregnancy in poor responders undergoing in vitro fertilization: a systematic review and meta-analysis. Fertil Steril. (2009) 91:749-66. doi: 10.1016/j.fertnstert.2007.12.077 
27. Li XL, Wang L, Lv F, Huang XM, Wang LP, Pan Y, et al. The influence of different growth hormone addition protocols to poor ovarian responders on clinical outcomes in controlled ovary stimulation cycles: a systematic review and meta-analysis. Medicine. (2017) 96:e6443. doi: 10.1097/MD.0000000000006443

28. Dakhly DMR, Bassiouny YA, Bayoumi YA, Hassan MA, Gouda HM, Hassan AA. The addition of growth hormone adjuvant therapy to the long down regulation protocol in poor responders undergoing in vitro fertilization: randomized control trial. Eur J Obstet Gynecol Reprod Biol. (2018) 228:1615. doi: 10.1016/j.ejogrb.2018.06.035

29. Keane KN, Yovich JL, Hamidi A, Hinchliffe PM, Dhaliwal SS. Singlecentre retrospective analysis of growth hormone supplementation in IVF patients classified as poor-prognosis. BMJ Open. (2017) 7:e018107. doi: 10.1136/bmjopen-2017-018107

30. Norman RJ, Alvino H, Hull LM, Mol BW, Hart RJ, Kelly TL, et al. Human growth hormone for poor responders: a randomized placebo-controlled trial provides no evidence for improved live birth rate. Reprod Biomed Online. (2019) 38:908-15. doi: 10.1016/j.rbmo.2019.02.003

31. Guan Q, Ma HG, Wang YY, Zhang F. [Effects of co-administration of growth hormone $(\mathrm{GH})$ and aspirin to women during in vitro fertilization and embryo transfer (IVF-ET) cycles]. Natl J Androl. (2007) 13:798-800.

32. Zhuang GL, Wong SX, Zhou CQ. [The effect of co-administration of low dosage growth hormone and gonadotropin for ovarian hyperstimulation in vitro fertilization and embryo transfer]. Zhonghua fu chan ke za zhi. (1994) 29:471-4.

33. Norman R, Alvino H, Hart R, Rumbauts L, LIGHT Study Investigators. A randomised double blind placebo controlled study of recombinant human growth hormone (h-GH) on live biorth rates in women who are poor responders. Hum Reprod. (2016) 31(Suppl. 1):i37.

34. Owen EJ, Shoham Z, Mason BA, Ostergaard H, Jacobs HS. Cotreatment with growth hormone, after pituitary suppression, for ovarian stimulation in in vitro fertilization: a randomized, double-blind, placebo-control trial. Fertil Steril. (1991) 56:1104-10. doi: 10.1016/S0015-0282(16)54 724-4

35. Bergh C, Hillensjo T, Wikland M, Nilsson L, Borg G, Hamberger L. Adjuvant growth hormone treatment during in vitro fertilization: a randomized, placebo-controlled study. Fertil Steril. (1994) 62:11320. doi: 10.1016/S0015-0282(16)56825-3

36. Suikkari A, MacLachlan V, Koistinen R, Seppala M, Healy D. Double-blind placebo controlled study: human biosynthetic growth hormone for assisted reproductive technology. Fertil Steril. (1996) 65:800-5. doi: 10.1016/S0015-0282(16)58217-X

37. Dor J, Seidman DS, Amudai E, Bider D, Levran D, Mashiach S. Adjuvant growth hormone therapy in poor responders to in-vitro fertilization: a prospective randomized placebo-controlled double-blind study. Hum Reprod. (1995) 10:40-3. doi: 10.1093/humrep/10.1.40

38. Eftekhar M, Aflatoonian A, Mohammadian F, Eftekhar T. Adjuvant growth hormone therapy in antagonist protocol in poor responders undergoing assisted reproductive technology. Arch Gynecol Obstet. (2013) 287:101721. doi: 10.1007/s00404-012-2655-1

39. Kucuk T, Kozinoglu H, Kaba A. Growth hormone co-treatment within a GnRH agonist long protocol in patients with poor ovarian response: a prospective, randomized, clinical trial. J Assist Reprod Genet. (2008) 25:1237. doi: 10.1007/s10815-008-9212-7

40. Bassiouny YA, Dakhly DM, Bayoumi YA, Hashish NM. Does the addition of growth hormone to the in vitro fertilization/intracytoplasmic sperm injection antagonist protocol improve outcomes in poor responders? A randomized, controlled trial. Fertil Steril. (2016) 105:697-702. doi: 10.1016/j.fertnstert.2015.11.026

41. Bayoumi YA, Dakhly DM, Bassiouny YA, Hashish NM. Addition of growth hormone to the microflare stimulation protocol among women with poor ovarian response. Int J Gynaecol Obstet. (2015) 131:3058. doi: 10.1016/j.ijgo.2015.05.034

42. Polyzos NP, Sunkara SK. Sub-optimal responders following controlled ovarian stimulation: an overlooked group? Hum Reprod. (2015) 30:20058. doi: 10.1093/humrep/dev149

43. Meldrum DR, Quaas AM, Su HI. Why is growth hormone underutilized for our most difficult IVF couples? Fertil Steril. (2018) 110:12612. doi: 10.1016/j.fertnstert.2018.09.003

44. Chen Y, Liu F, Nong Y, Ruan J, Guo Q, Luo M, et al. Clinical efficacy and mechanism of growth hormone action in patients experiencing repeat implantation failure. Can J Physiol Pharmacol. (2018) 96:92932. doi: 10.1139/cjpp-2017-0786

45. Altmae S, Mendoza-Tesarik R, Mendoza C, Mendoza N, Cucinelli F, Tesarik $\mathrm{J}$. Effect of growth hormone on uterine receptivity in women with repeated implantation failure in an oocyte donation program: a randomized controlled trial. J Endocrine Soc. (2018) 2:96-105. doi: 10.1210/js.2017-00359

Conflict of Interest Statement: RH is the Medical Director of Fertility Specialist of Western Australia and a shareholder in Western IVF, he has received educational sponsorship from MSD, Merck-Serono and Ferring Pharmaceuticals.

Copyright (C) 2019 Hart. This is an open-access article distributed under the terms of the Creative Commons Attribution License (CC BY). The use, distribution or reproduction in other forums is permitted, provided the original author(s) and the copyright owner(s) are credited and that the original publication in this journal is cited, in accordance with accepted academic practice. No use, distribution or reproduction is permitted which does not comply with these terms. 